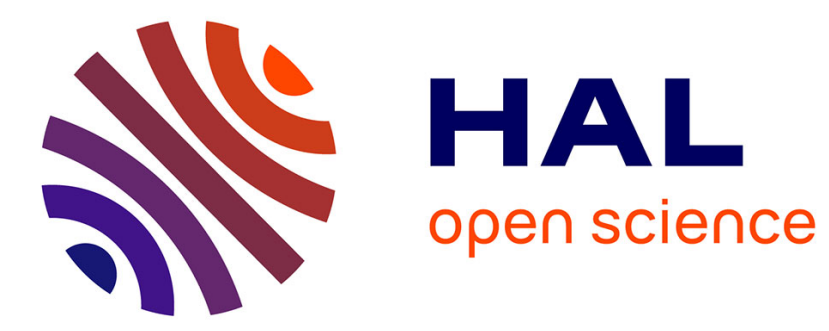

\title{
Design, static modeling and simulation of a 5-DOF precise piezoelectric positioner.
}

Abdenbi Mohand Ousaid, Dominique Gendreau, Patrick Rougeot, Micky

Rakotondrabe

\section{- To cite this version:}

Abdenbi Mohand Ousaid, Dominique Gendreau, Patrick Rougeot, Micky Rakotondrabe. Design, static modeling and simulation of a 5-DOF precise piezoelectric positioner.. Sensors for Next-Generation Robotics, Apr 2016, Baltimore, United States. hal-02868203

\section{HAL Id: hal-02868203 \\ https://hal.science/hal-02868203}

Submitted on 15 Jun 2020

HAL is a multi-disciplinary open access archive for the deposit and dissemination of scientific research documents, whether they are published or not. The documents may come from teaching and research institutions in France or abroad, or from public or private research centers.
L'archive ouverte pluridisciplinaire HAL, est destinée au dépôt et à la diffusion de documents scientifiques de niveau recherche, publiés ou non, émanant des établissements d'enseignement et de recherche français ou étrangers, des laboratoires publics ou privés. 


\title{
Design, static modeling and simulation of a 5-DOF precise piezoelectric positioner
}

\author{
Abdenbi Mohand-Ousaid*, Dominique Gendreau, Patrick Rougeot \\ and Micky RaKotondrabe \\ AS2M department, FEMTO-ST Institute \\ University of Franche-Comté / CNRS UMR6174 / UBFC / ENSMM / UTBM \\ 24, rue Alain Savary \\ 25000 Besancon France
}

\begin{abstract}
This paper presents the design, the static modeling and the performances simulation of a five degrees of freedom precise poistioner. Based on piezoelectric stack actuators, the positioner is able to perform high resolution $\mathrm{x}-\mathrm{y}-\mathrm{Z}$ linear motions and angular motions about $\mathrm{x}$ and about $\mathrm{y}$ axes. After presenting the design, the static modeling is carried out in order to understand the functioning of the positioner. The simulation of the model is afterwards carried out to estimate the ranges of motions that it can perform. The positioner is very promising in various applications that require dexterity and high resolution displacement such as images scanning with atomic force microscopes, micromanipulation or microassembly, etc.
\end{abstract}

Keywords: nano/micro positioner, additive manufacturing, 3D printing, numerical simulation, piezo-stack actuators.

\section{INTRODUCTION}

Nowadays, the use of micro/nano positioners to manipulate and characterize small objects is considerable, and their significance and contribution have been proved in different applications. Thanks to smart materials, in particular piezoelectric materials, and to flexure mechanism, micro or submicrometric positioning resolution, high dynamics (tens or hundreds of Hertz), repeatable motion and vacuum compatibility are reachable and several options and capabilities can be explored at small scales. Piezoelectric systems have paved the way for a wide range of applications like image scanning AFM (atomic force microscopy), microassembly, micromanipulation ( of bio or artificial objects), micro/nano manufacturing, active sensing and so on.$^{1-3}$ Though used for many years, their studies and development still remain nowadays an attractive subject because of the various challenges raised in precise positioning applications. For instance, having a dexterous system as a complementary to an AFM could improve the images scanning ranges, dynamics and samples possibilities.

Many designs have been studied for dexterous or multi-DOF (degrees of freedom) miniaturized precise positioning systems. Recently, Li and Xu proposed a XYZ totally decoupled parallel kinematics nano-positioning stage based on flexure mechanism driven by PZT actuators. ${ }^{4}$ Likewise, a 3-DOF (degrees of freedom) piezoelectric nanopositioner based on piezoelectric stacks actuators has been developed in. ${ }^{5}$ It includes capacitive sensors that permit to measure the displacements along the $\mathrm{X}$-axis and the $\mathrm{Y}$-axis. Another development is presented in. ${ }^{6}$ Both developments employ the serial configuration to obtain the three DOF. $\operatorname{In}^{7}$, a parallel-kinematic configuration was introduced to develop a 2-DOF (XY) piezoelectric nanopositioner. The same configuration was proposed in $^{8}$ for another 2-DOF nanopositioner. Last but not least, a redundant nanopositioner based on the dual-range configuration was proposed in $^{9}$ which allows two levels of resolution and ranges.

Although the above mentioned systems were demonstrated theoretically as well as experimentally, the number of degrees of freedom remains inconvenient and insufficient to achieve complex manipulations that require more dexterity and several DOF. For example, atomic force microscopy applications illustrate well this issue when

\footnotetext{
* Further author information: (Send correspondence to Abdenbi Mohand-Ousaid): E-mail: abdenbi.mohand@femtost.fr
} 
dealing with the orientation of the sample, which requires more axes than $\mathrm{X}$ and $\mathrm{Y}$. To overcome those limitations, we propose in this paper a new approach. Instead of using planar structures which constrain the number of DOF to three or fewer, we propose to develop a 5-DOF 3D monolithic structures. Indeed we think that the rapid advancing on additive manufacturing, especially 3D printing, can offer new perspectives to design innovative micro/nano positioners. These processes enable for example to design 3D complex monolithic macro-structures as well as micro-structures. Taking advantage of this new technology, the positioner structure could be designed as a monolithic structure in order to reduce mechanical plays and consequently to maintain a high resolution. The proposed design here consists of a monolithic passive structure "Skeleton" driven by six piezo-stack actuators. In the first time, the system structure is optimally designed to achieve the five DOF and is afterwards fabricated using additive manufacturing process. Then, the structure is equipped with piezoelectric stack actuators. In terms of performances, the system is able to generate high resolution linear displacement along X-Y-Z axes and angular displacement about X-Y axes. Both the proposed approach of fabrication and the number of DOF constitute the novelty comparing to the above cited works.

This paper is composed of six sections. A brief introduction to 3D printing and the system design are addressed in section II. After the design, the static modeling is presented in section III. Section IV deals with the simulation of the system using the finite element COMSOL-Multiphysics software in order to assess systems performances. Section V discusses on the simulation results. Last section summarizes the work.

\section{SYSTEM DESIGN}

Additive manufacturing contribution is growing increasingly in several applications (bio-medical, robotics, mass customized product, etc) and receives increased interest. ${ }^{10}$ This new technology brings a reel rupture comparing to conventional technology in terms of manufacturing and design. As shown in ${ }^{11-14}$ several complex structures have been made possible by additive manufacturing. These samples show clearly the power of 3D printing as a promising solution offering new perspectives to design innovative three dimensional structures. The literature related to this technology is abundant ${ }^{13,15-18}$. Basically, with such technology, three-dimensional CAD models can be fabricated and realized directly by adding or combining material layer by layer as illustrated in Fig 1. Until now, almost all existing 3D printing technologies use passive materials. This means that the printed structures are "passive structures" without functionalities (actuation, sensing, energy harvesting...). Of course, the approach will be certainly more interesting if $3 \mathrm{D}$ printer would be able to combine active material like piezoelectric materials with passive material.

a

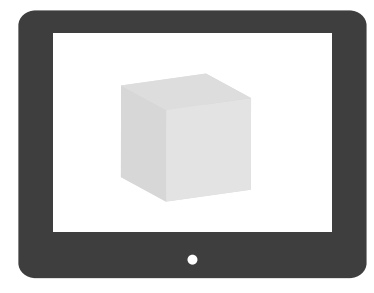

3D CAD model b

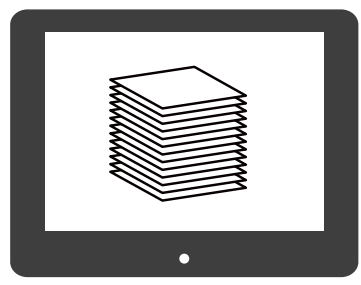

sliced 3D model c

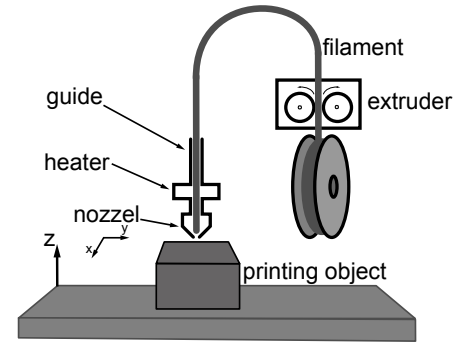

3D printer (layer by layer fabrication) d

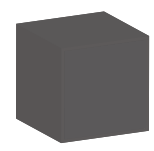

printed model

Figure 1. 3D printing principle and steps. a) 3D model design using CAD software, b) 3D model sliced using STL format (before the printing step), c) Printing step based on the STL data 3D, the printing being layer by layer, d) three-dimensional final product ready for use.

In this paper, we propose to design the skeleton of a complex 5-DOF system as a monolithic structure and actuate it using commercial piezostack actuators. Made possible by 3D technology (3D printing, 3D design, ...), the proposed monolithic construction reduces mechanical plays, increases accuracy and maintains high resolution. In terms of kinematics, we have chosen a symmetric serial configuration which is compact and easy to implement. Within this configuration, four single-beam symmetric flexures are used to guide the structure linear displacements along $\mathrm{X}$ axis as well as along $\mathrm{Y}$ axis while symmetric cross-beams are used to guide the 
a

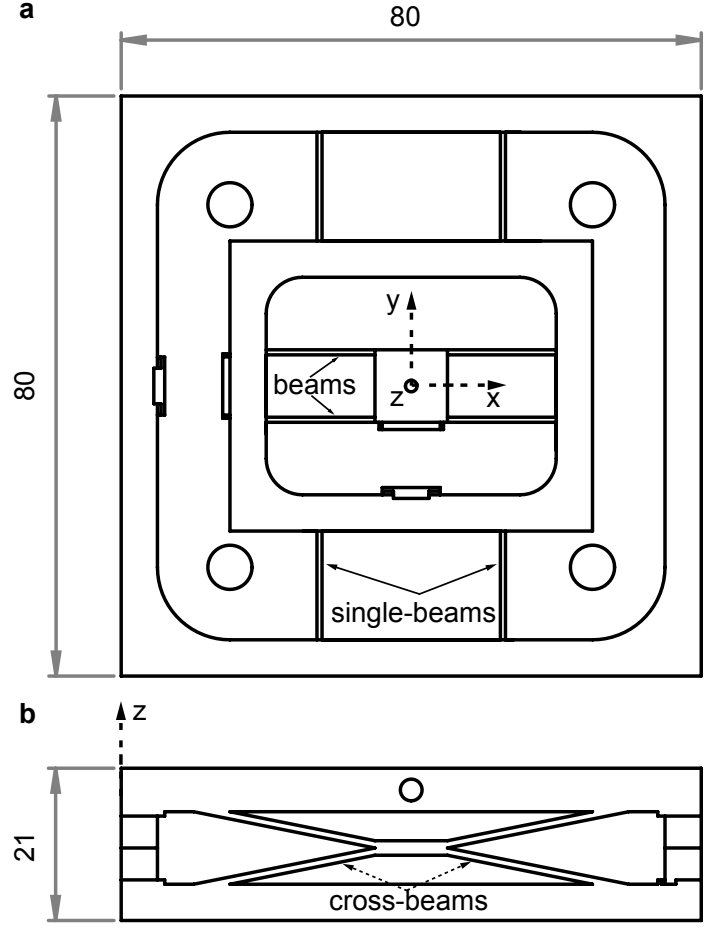

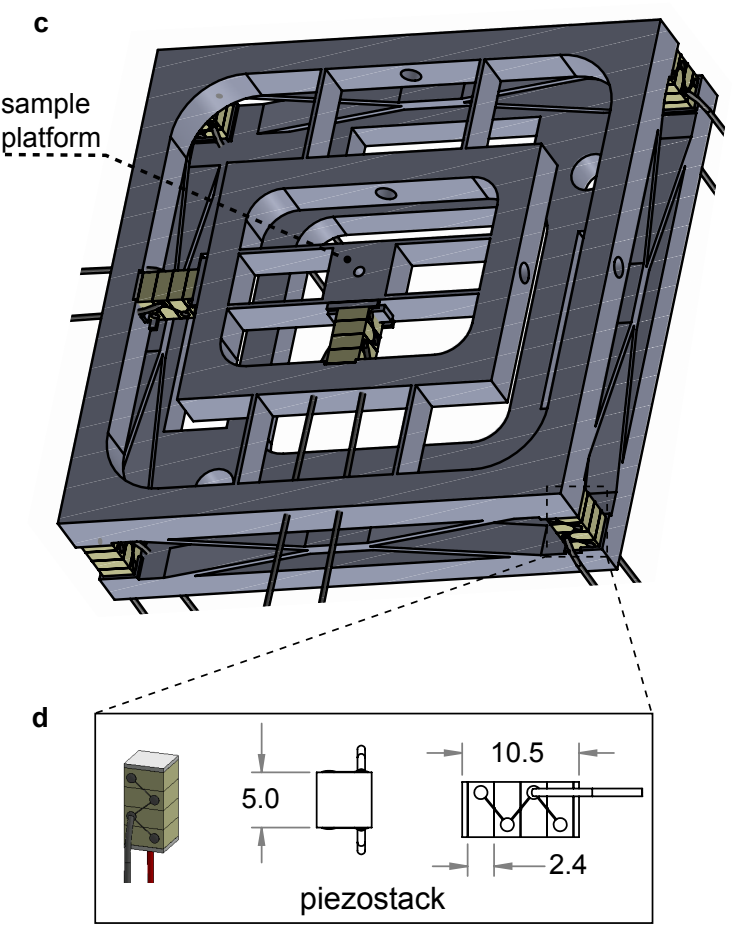

Figure 2. 3D CAD model of the proposed positioner which consists of a monolithic passive structures driven by six piezostack actuators. a) top view of the positioner structure without actuators. b) side view of the structure. c) Isometric view of the positioner structure equipped with six piezostack actuators. d) the piezoelectric stack actuators (piezostacks).
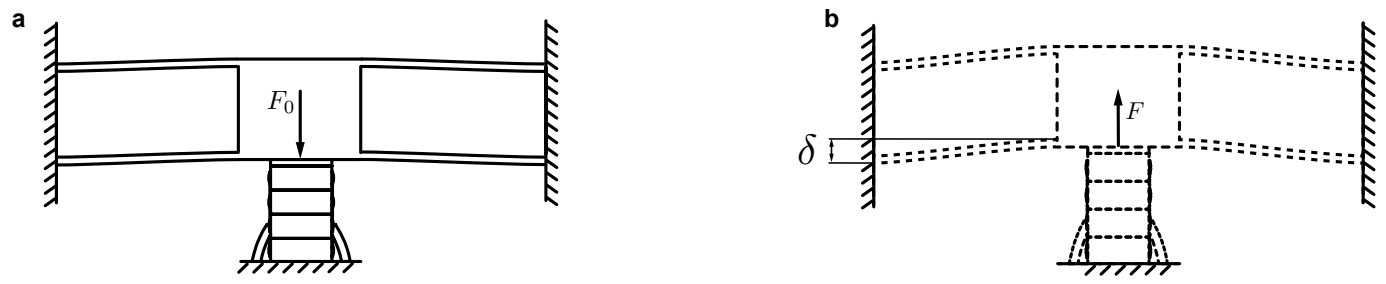

Figure 3. Static behavior of the structure: study of the X axis. (a): initial position. (b): X linear displacement.

structure linear displacement along $\mathrm{Z}$ axis and angular displacements about $\mathrm{X}$ and $\mathrm{Y}$ axes (Fig. 2(a) and Fig. 2(b) respectively). Mechanical stops are considered in the design in order to guide the piezostack actuators during the assembly process and to block them when placed. In addition, to avoid any play that might result from assembly, all actuators are preloaded. To respect those constraints a CAD model given in Fig. 2(c) is designed using SolidWorks ${ }^{\circledR}$. This design illustrates the details about the whole structure of the positioner in particular skeleton architecture and actuators distribution. In terms of actuation, piezostack actuators from Thorlabs are used (see Fig. 2(d)). They consist of a multiple chips which are bonded via epoxy and glass beads. Allowing a maximum displacement of $11.2 \mu \mathrm{m}$ such actuators offer high resolution, high dynamics, repeatable motion and so on, whereas their stroke is limited. This common limitation to piezostack actuators was tackled in many studies by using amplification mechanisms. However, it was not the case in this work. It is important to notice that the chosen structure is not fortuitous. Additionally to its simplicity, we do not use any amplification mechanism since one of the main objective of this work is to assess the advantages that $3 \mathrm{D}$ printing could bring to design micromechatronics systems. In terms of size, the system has a width of $80 \mathrm{~mm}$, a length of $80 \mathrm{~mm}$ and a height of $21 \mathrm{~mm}$. The detailed system dimensions are given further in section 4 . 


\section{STATIC MODELING}

This section deals with the static modeling of the 5-DOF precise positioning system designed above. It aims to determine the static relationship between the displacement of the positioner and the supply voltage applied to actuate the piezostack. To this end, two assumptions were made. The first deals with the deformation of the structure itself which is considered to be elastic and linear, i.e. small deformations. This means that the force $F$ applied to a part of the structure, for instance from the external or from the piezostack actuators, produces a displacement $\delta$ as in equation (1), where $k$ is the structure stiffness which depends on the structure architecture. Let us call $k_{x}, k_{y}, k_{z}, k_{r x}, k_{r y}$ the structure stiffness along $\mathrm{X}, \mathrm{Y}, \mathrm{Z}$ axes and about $\mathrm{X}, \mathrm{Y}$ axes respectively, observed at the points where the piezostacks actuate it. As the structure is symmetric, $k_{r x}$ is expected to be equal to $k_{r y}$. The second assumption deals with the (static) behavior of each piezostack actuator: the displacements produced by the piezostack actuator is linear versus the applied voltage $U$ and versus any external force $F_{s}$ applied to it. This relation is given by equation (2), where $U$ ranges within $0 \rightarrow 75 \mathrm{~V}$. Here $F_{s}$ is the force due to the reaction of the structure which is opposite to the force given in equation (1).

$$
\begin{gathered}
F=k \delta \\
\delta=\alpha U+\beta F_{s}
\end{gathered}
$$

By combining equations above, we can easily determine the static behavior of the structure. To do so, let's take the case of $\mathrm{X}$ linear motion as illustrated in Fig. 3 where a piezostack actuator preloaded with a force $F_{0}$ is pushing a shuttle guided with four parallel beams. According to the equation (2), the displacement $\delta_{x}$ of the shuttle could be written as following:

$$
\delta_{x}=\alpha U_{x}+\beta\left(F_{x}+F_{0}\right)
$$

where

$$
F_{x}=-k_{x} \delta_{x}
$$

$F_{x}$ being the force $F_{s}$ applied to the piezostack of the $\mathrm{X}$ axis, as reaction of the structure.

By substituting (3) into (4) we obtain the static expression of the force applied to actuate the structure along $\mathrm{X}$ axis is derived:

$$
F_{x}=\frac{1}{1+k_{x} \beta}\left(-k_{x}\left(\alpha U+\beta F_{0}\right)\right)
$$

This equation represents the force applied to actuate the structure along $\mathrm{X}$ direction as well as $\mathrm{Y}$ direction since the mechanisms used to guide the shuttle along these axes have the same architecture. In fact, the dimensions of the four bars for the $\mathrm{Y}$ axis are similar to those of the $\mathrm{X}$ axis. However, the shuttle of $\mathrm{Y}$ axis is different from that of $\mathrm{X}$ axis, as illustrated in Fig. 2. Meanwhile we can assume that the shuttle only affects the dynamic behavior, not the static one, as it works as an inertia. In response to this force a displacement will be generated. This displacement is also obtained by substituting equation (4) in equation (3). We obtain:

$$
\delta_{x}=\alpha \frac{U}{1+\beta k_{x}}-\beta \frac{1}{1+\beta k_{x}} F_{0}
$$

To study the movements along the $\mathrm{Y}$ and $\mathrm{Z}$ axes as well as the angular motions about $\mathrm{X}$ and $\mathrm{Y}$ axes, the same procedure is repeated. For that, the stiffness $k$ and the pre-load force $F_{0}$ should be updated according to each axis. Regarding the coefficients $\alpha$ and $\beta$, they depend on the features of the actuators. They are furnished in the commercial datasheet of the actuators. They can also be experimentally determined as the maximum free displacement (zero force) for $\alpha$ and as the blocking force (zero displacement) for $\beta$, both obtained at the maximum of supply voltage. Their numerical values are given in section 4 . 

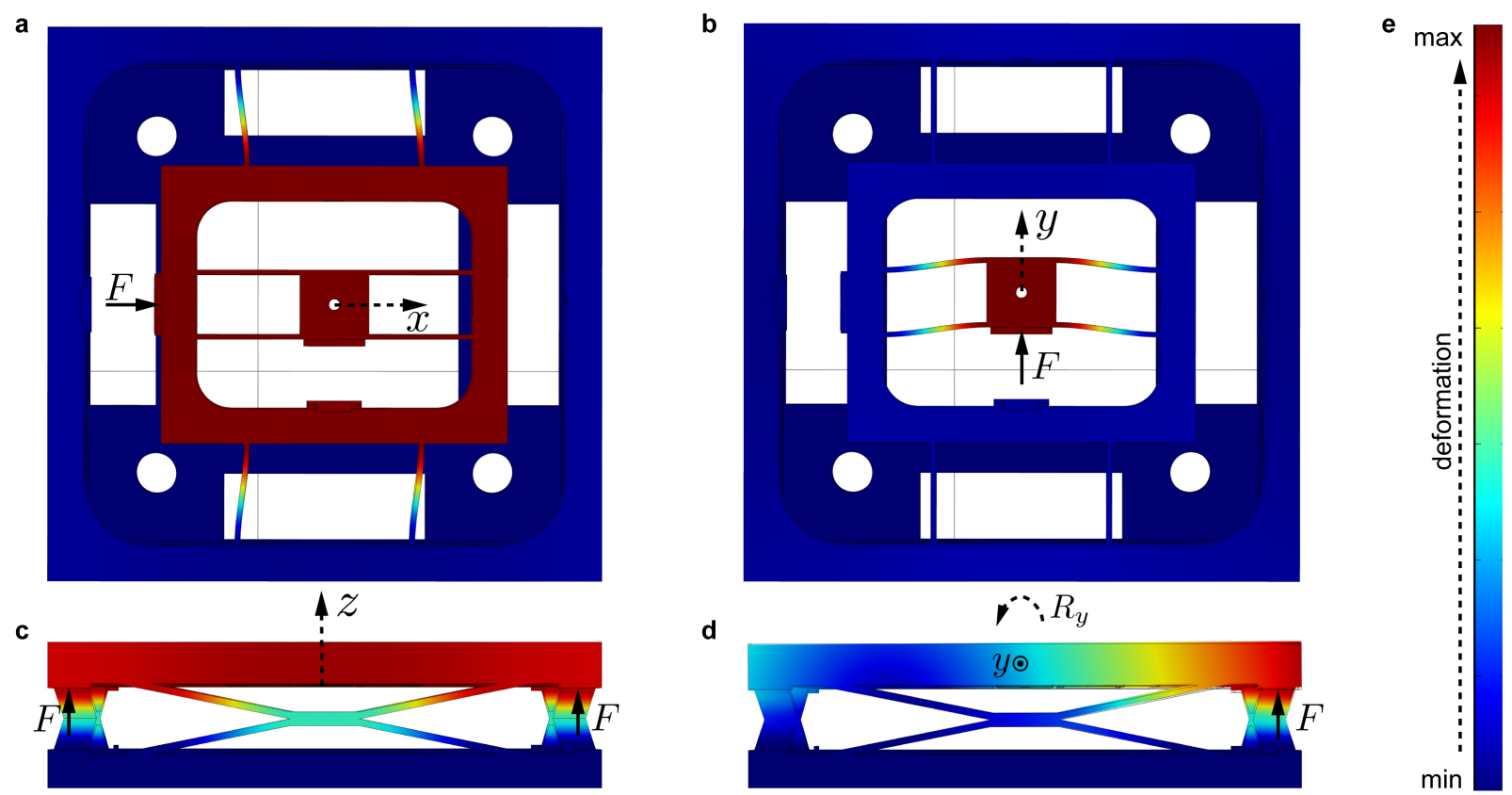

Figure 4. Simulation results showing the deformation of the structure in response to load force. a) structure deformation along $\mathrm{X}$ axis. b) structure deformation along $\mathrm{Y}$ axis. c) structure deformation along $\mathrm{Z}$ axis. d) structure deformation when performing angular motion about $\mathrm{X}$ axis, which is the same than that of about $\mathrm{Y}$ axis (by symmetry). e) figure legend. For better view, all deformations are exaggerated.

\section{STATIC PERFORMANCES SIMULATION}

This section aims to evaluate the static performances of the designed positioner by carrying out finite-element analysis (FE) simulation using COMSOL Multiphysics ${ }^{\circledR}$ software. To do so, the CAD model of the positioner is converted to "stl" format and then imported into the FE software. First, the stiffnesses of the structure for the displacement along the $\mathrm{X}, \mathrm{Y}$ and $\mathrm{Z}$ axes are determined by simulating the behavior of the structure when applying a load force. They correspond to $k_{x}, k_{y}$ and $k_{z}$. Then the obtained stiffnesses are used to simulate the force generated by the piezostack according to the equation given in the previous section (section 3 ). After that, this force is applied to simulate the linear displacements of the structure along $\mathrm{X}, \mathrm{Y}$ and $\mathrm{Z}$ axes using the analytical model. The same procedure is repeated to evaluate the stiffnesses for the angular motion about $\mathrm{X}$ and $\mathrm{Y}$ axes. All the parameters related to the dimensions of the positioner structure are shown in Fig. 5 and the proprieties of the material utilized to simulate the positioner behavior are listed in table 1 (material: VisiJet Crystal). To summarize, the FE simulation has two objectives. First it is used to identify the stiffnesses of the structure $\left(k_{x}, k_{y}, k_{z}, k_{r x}\right.$ and $\left.k_{r y}\right)$ which are initially unknown. The stiffnesses are required for the simulation of the analytical model. The second objective of the FE simulation is to have displacements behavior of the structure. The simulated behavior from FE is afterwards compared with the simulated behavior from the analytical model.

\subsection{Structure stiffnesses}

As pointed in the previous section (section 3), structure stiffnesses remain one of the parameters to determine in order to simulate the behavior of the positioner. Assuming that the deformations are elastic and linear, one stiffness is simply the ratio between the applied force and the produced displacement. So, we carried out FE simulation to evaluate the structure stiffness. Figures $4(\mathrm{a})(\mathrm{b})$ and (c) show the results where a load force within a range of $0 \rightarrow 1 \mathrm{~N}$ is applied along $\mathrm{X}, \mathrm{Y}$ and $\mathrm{Z}$ directions, while Fig. 4(d) shows the simulation results related to the structure in rotation about $\mathrm{Y}$ axis (rotation about $\mathrm{X}$ axis is the same). The simulations results show also the interest of the different beams to guide the structure displacements. As expected, the deformation behavior of the structure is elastic which means that the stiffness is a constant parameter. The resulted stiffnesses are summarized in table Table 4.1. In addition to numerical value, theoretical values obtained from structural 


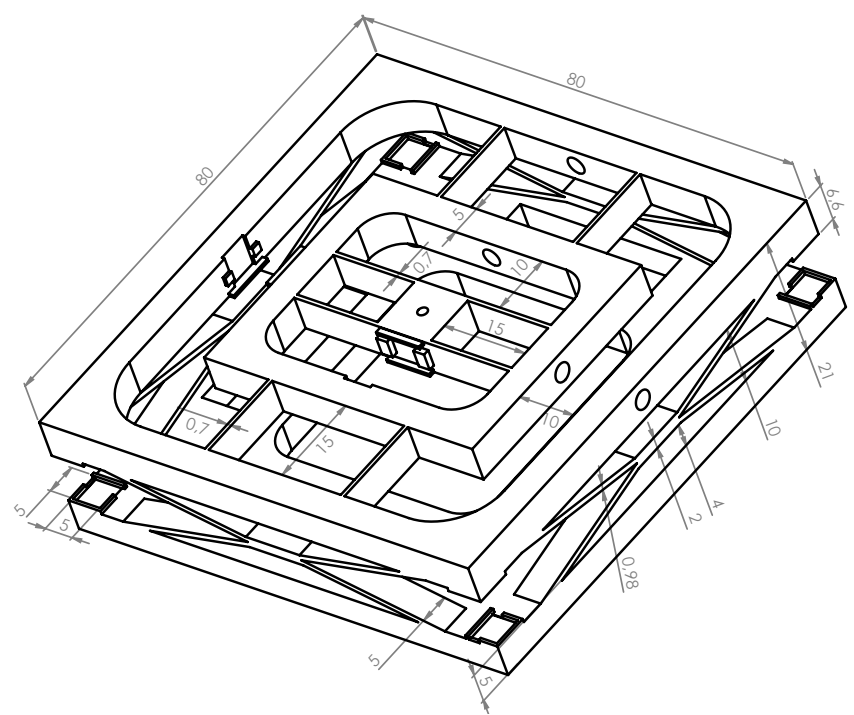

Figure 5. Main positioner dimensions (all dimensions are in $\mathrm{mm})$.
Table 1. VisiJet M3 Crystal proprieties.

\begin{tabular}{l|l} 
Proprieties & VisiJet Crystal \\
\hline \hline density at $80^{\circ} \mathrm{C}$ (liquid) & $1.02 \mathrm{~g} / \mathrm{cm}^{3}$ \\
\hline tensile strength & $42.4 \mathrm{Mpa}$ \\
\hline tensile modulus & $1463 \mathrm{Mpa}$ \\
\hline elongation at break & $6.83 \%$ \\
\hline flexural strength & $49 \mathrm{Mpa}$ \\
\hline poisson coefficient & 0.35 \\
\hline \hline
\end{tabular}

mechanics formula are given for $\mathrm{X}$ and $\mathrm{Y}$ direction. From this table, one can notice a small difference between the theoretical and the numerical value of the stiffness along $\mathrm{Y}$ axis of $6 \%$. This difference is due mainly to the serial kinematic configuration. When a piezostack pushes in $\mathrm{Y}$ direction, the structure carrying the piezo pushes also on the four beams parallel to $\mathrm{Y}$ direction which tends to reduce the rigidity of the positioner in this direction. However, in $\mathrm{X}$ direction the difference is about $0.28 \%$ which can be neglected. As the structure used to guide the displacement along $\mathrm{Z}$ and rotation about $\mathrm{X}, \mathrm{Y}$ is complex, we evaluated only the numerical value of the stiffness.

\begin{tabular}{c|c|c|c} 
stiffness & theoretical stiffness model & numerical simulation & model error \\
\hline \hline$k_{x}(\mathrm{~N} / \mathrm{m})$ & 3568 & 3558 & $0.28 \%$ \\
\hline$k_{y}(\mathrm{~N} / \mathrm{m})$ & 3568 & 3330 & $6 \%$ \\
\hline$k_{z}(\mathrm{~N} / \mathrm{m})$ & - & $15310^{3}$ & - \\
\hline$k_{r x}(\mathrm{~N} / \mathrm{m})$ & - & $30.510^{3}$ & - \\
\hline$k_{r y}(\mathrm{~N} / \mathrm{m})$ & - & $30.510^{3}$ & - \\
\hline \hline
\end{tabular}

Table 2. stiffness evaluation by theory (structural mechanics) model and simulation.

\subsection{Piezostack specifications}

As pointed in section 2, piezostack actuators "PK2FMP2" from Thorlasbs are used for our application. The main specifications of this actuator are summarized in table 4.2. Such actuators provide a maximum displacement of $11.2 \mu \mathrm{m}$ in free stroke and a blocking force of $1000 \mathrm{~N}$. The voltage range is of $0 \rightarrow 75 \mathrm{~V}$ and the coefficients $\alpha$ and $\beta$ are $0.1493 \mu \mathrm{m} / \mathrm{V}$ and $-0.0112 \mu \mathrm{m} / \mathrm{N}$ respectively.

\begin{tabular}{c|c} 
specification & quotation \\
\hline \hline supply voltage range & maximum: $0-75 \mathrm{~V}$ \\
\hline displacement (free stroke) at $75 \mathrm{~V}$ & $11.2 \mu \mathrm{m} \pm 15 \%$ \\
\hline blocking force at $75 \mathrm{~V}$ & $1000 \mathrm{~N}$ \\
\hline \hline
\end{tabular}

Table 3. PK2FMP2 piezostack specifications. 

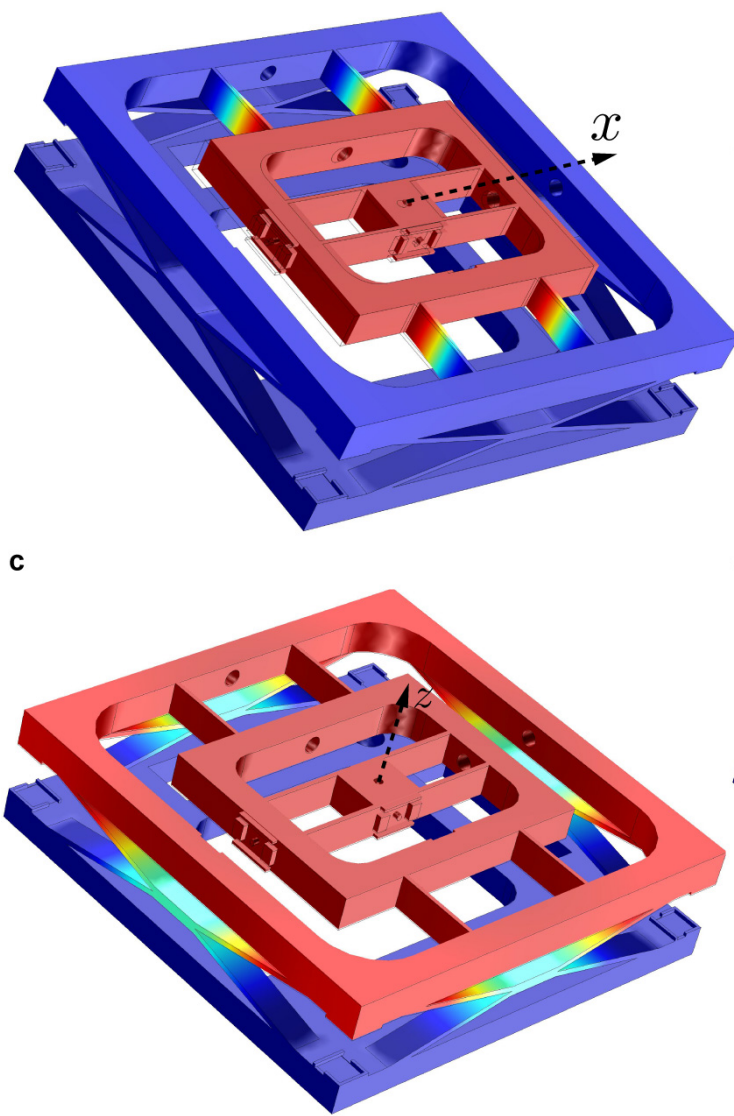

b

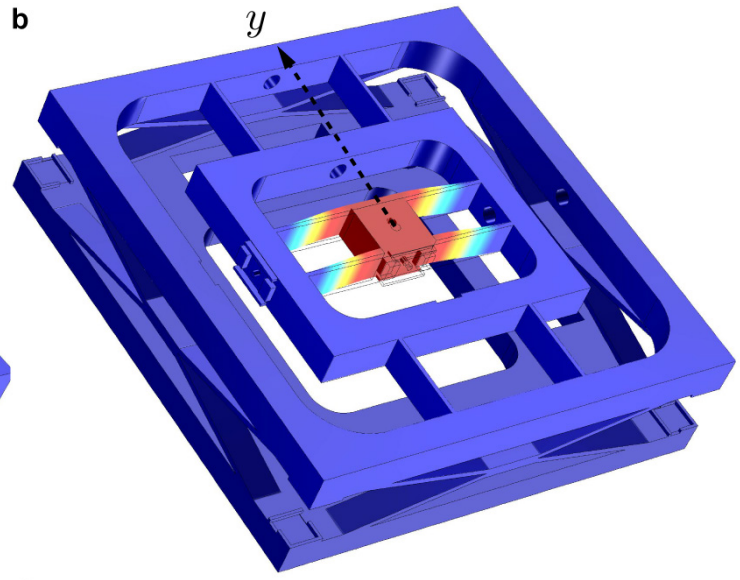

d

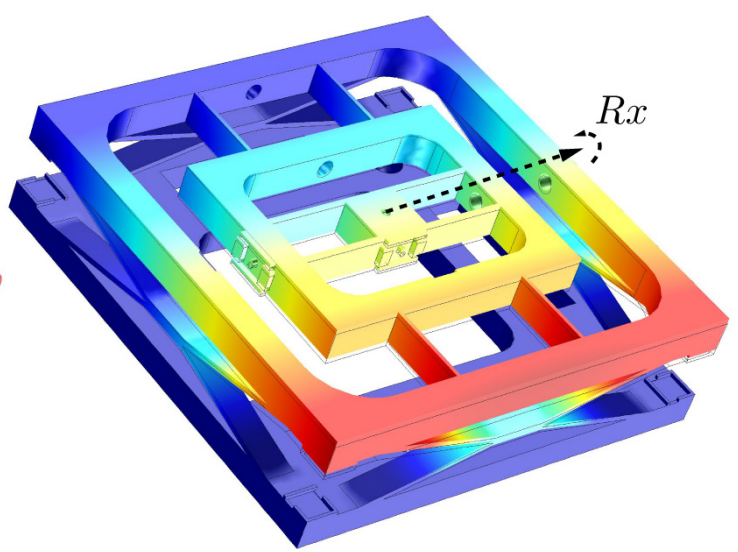

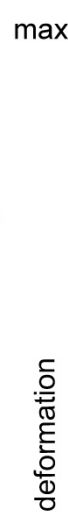

$\min$

Figure 6. Simulation results of the displacement of the positioner under COMSOL. a) displacement along X axis. b) displacement along $\mathrm{Y}$ axis. b) displacement along $\mathrm{Z}$ axis. d) rotation about $\mathrm{X}$ axis.

\subsection{Simulation of the displacement toward $\mathrm{X}$ and $\mathrm{Y}$ axes}

Once the stiffness along each axis is determined, we carried out simulation to assess the displacement toward $\mathrm{X}$ and $\mathrm{Y}$ axes. For that, we applied a load force which is generated according to equation (5) given in section 3. This equation gives the relationships between the applied voltage to the piezostack and the generated force taking into account the uodated blocking force due to the four single-beam guide. First, the load force is applied along X axis and then the same force is applied along $\mathrm{Y}$ axis. Figures 6(a,b) illustrate how the positioner behaves in response to the applied force along $\mathrm{X}$ and $\mathrm{Y}$ axes separately. In Fig. 7.(a,b), a comparison is made between the numerical simulation displacement and the theoretical displacement given by equation (6) (section 3). The obtained curves indicate a very good match. In addition, one can see from the result that the maximum displacement of the structure is the same as the maximum displacement of the expected piezoelectric stack. This mean that the displacement range along $\mathrm{X}$ and $\mathrm{Y}$ axes goes from $0 \mu \mathrm{m}$ to $11.2 \mu \mathrm{m}$.

\subsection{Simulation of the displacement toward $\mathrm{Z}$ axis}

Similar to the previous simulation, vertical displacement is assessed by applying load force along $\mathrm{Z}$ axis according to the distribution of the four vertical actuators. To this end, the equation (5) given in section 3 is also utilized. Likewise the previous simulation, this equation gives the relationships between the applied voltage and the generated force. In this case, the $\mathrm{Z}$ displacement is caused by four actuators. This means that the total applied force along $\mathrm{Z}$ axis is the sum of each force generated by the four actuators. Figures 6(c) shows how the positioner behaves in response to the applied force along $\mathrm{Z}$ axis. In addition, Fig. 7.(c) presents a comparison between the 

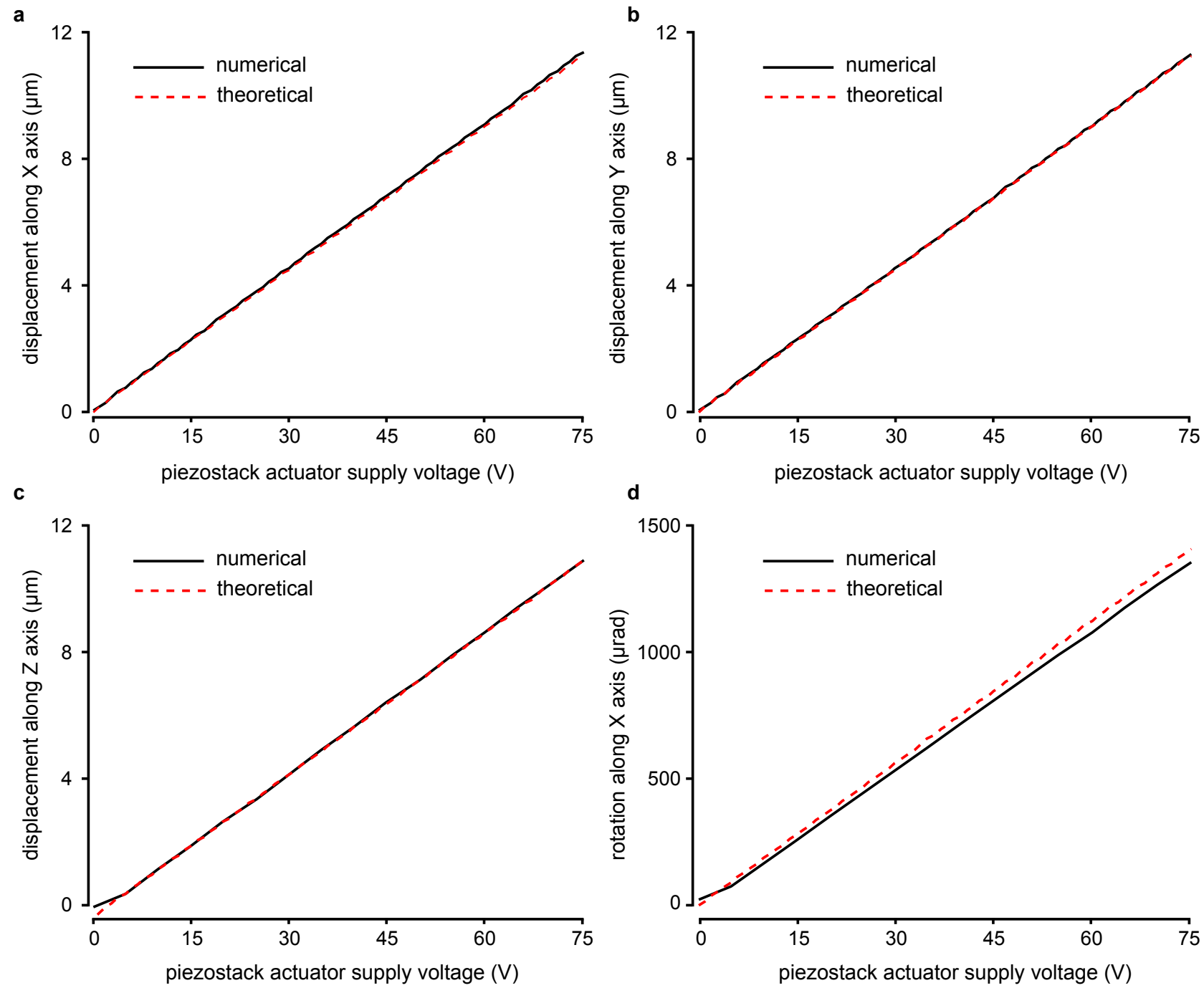

Figure 7. Results of numerical simulation under COMSOL Multiphysics. a) displacement along X axis versus supply voltage. b) displacement along $\mathrm{Y}$ axis versus supply voltage. c) displacement along $\mathrm{Z}$ axis versus supply voltage. d) rotation about $\mathrm{X}$ axis versus supply voltage. Solid and dashed lines represent the numerical and the theoretical displacements respectively.

numerical and the theoretical displacements where the obtained curves indicate clearly a very good match. the result indicates also that the displacement range achieved along $\mathrm{Z}$ goes from $0 \mu \mathrm{m}$ to $11.2 \mu \mathrm{m}$.

\subsection{Simulation of rotation toward $\mathrm{X}$ and $\mathrm{Y}$ axes}

Likewise the previous simulation, rotation displacement is assessed by applying load force around X or Y axes. For that, only two actuators are utilized. For this case, reader can refer to Fig 6(d) which shows the rotation behavior of the positioner in response to an applied force. Reader can also refer to Fig. 7.(d) where a comparison is made between the numerical simulation and the theoretical displacements. The resulted curves indicate a little bit difference that can be neglected. The result indicates also that the rotation range achieved by the positioner goes from $0 \mu \mathrm{rad}$ to $1500 \mu \mathrm{rad}$. 

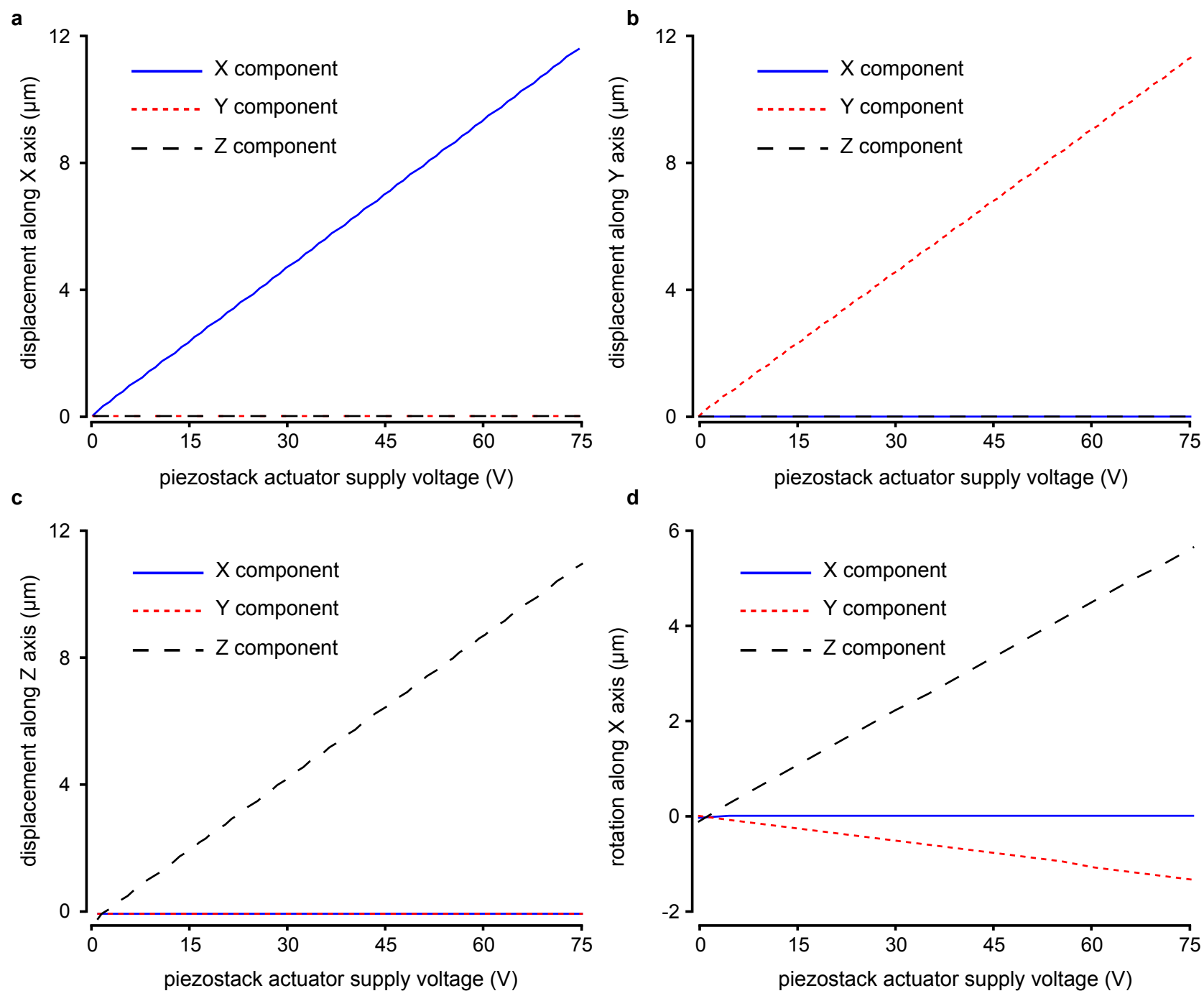

Figure 8. Coupling analysis of the positioner according to each DOF. a) coupling analysis when the positioner is moving along $\mathrm{X}$ axis. b) Coupling analysis when the positioner is moving along Y axis. c) Coupling analysis when the positioner is moving along $\mathrm{Z}$ axis. d) Coupling analysis when the positioner is rotating about $\mathrm{X}$ axis. Solid blue line, dashed black line and dashed red line represent the $\mathrm{X}, \mathrm{Y}$ and $\mathrm{Z}$ component of the center of the positioner respectively.

\subsection{Coupling analysis}

In parallel to the simulation carried out to evaluate the displacement of the positioner, we studied the coupling between each axis. For this end, we evaluate the displacement that might be generated along each axis when a load force is applied only along one axis. Figure 8 presents the simulation results obtained when a load force is applied respectively along X (see Fig 8(a)), Y (see Fig 8(b)), Z (see Fig 8(c)) axes and rotation about X axis (see Fig $8(\mathrm{~d})$ ). For each figure of the board, we plotted the three component (X,Y and Z) of the center point of the sample platform according to the supply voltage applied to the piezostack actuator. According to the results, one can see clearly from the curves that $\mathrm{X}, \mathrm{Y}$ and $\mathrm{Z}$ axes are totally decoupled. However, we observe a coupling when the positioner rotations as shown in Fig 8(c). The result shows a displacement along $\mathrm{Z}$ axis which is normal, but it introduces a coupling effect along Y axis. This coupling could be vanished by using a piezoelectric actuators that could generate a positive displacement as well as negative displacement which is not the case in this study. Piezostack actuators only generate positive displacements. 


\section{CONCLUSION}

In summary, this paper presents the design and the static modeling and analysis of a piezoelectric positioner which is not subjected to play. It is based on a passive monolithic three-dimensional structure equipped with six piezostack actuators. The positioner is able to perform 5-DOF (three translations along X,Y,Z axes and two rotations about $\mathrm{X}, \mathrm{Y}$ axes) and is manufactured thanks to additive manufacturing which gives options and capabilities to manufacture such as monolithic three-dimensional structures. To understand and validate the positioner functioning, a static modeling is performed and numerical simulation under COMSOL Multiphysics were carried out respectively. As a result, the positioner performs a motion within a range of $11.2 \mu \mathrm{m}$ along each axis. The positioner is very promising in various applications that require dexterity and high resolution displacement such as image scanning force microscopy.

Ongoing and future works include the dynamic analysis of the positioner and its realization by using an appropriate additive manufacturing process. Future works will focus also on the issues that could raise when 3D printing technology is used such as temperature sensitive and limited printing resolution. Then, the work will focus on the characterization of the positioner in terms of displacement and coupling, the control and its applications to precise positioning tasks. Future work is also concerned with extending the capabilities of the postionner to

6 -DOF and the use of methodologies of design such as in ${ }^{19,20}$ in order to optimize the structure dimensions and the performances. These designs are based on control theory tools such as interval techniques ${ }^{21}$

\section{Acknowledgment}

This work is supported by the national ANR-JCJC C-MUMS-project (National young investigator project ANR12-JS03007.01: Control of Multivariable Piezoelectric Microsystems with Minimization of Sensors). This work is also supported by the CNRS PEPS-JCJC (COSMMOT) project and by the LABEX ACTION (ANR-11LABX-0001-01) project. Authors gratefully acknowledge those supports.

\section{REFERENCES}

[1] J. Agnus, N. Chaillet, C. C. S. D. M. G. Y. H. G. L. P. L. N. P. K. R. M. R. and Tamadazte, B., "Robotic microassembly and micromanipulation at femto-st," Journal of Micro-Bio Robotics 8(2), 91-106 (2013).

[2] Rakotondrabe, M., "Smart materials-based actuators at the micro/nano-scale: characterization, control and applications," Springer-Verlag (2013).

[3] S. Devasia, E. E. Eleftheriou, R. M., "A survey of control issues in nanopositioning," IEEE Transactions on Control Systems Technology (2007).

[4] Li, Y. and Xu, Q., "A totally decoupled piezo-driven xyz flexure parallel micropositioning stage for micro/nanomanipulation," Automation Science and Engineering, IEEE Transactions on 8(2), 265-279 (2011).

[5] Kenton, B. J. and Leang, K. K., "Design and control of a three-axis serial-kinematic high-bandwidth nanopositioner," Mechatronics, IEEE/ASME Transactions on 17(2), 356-369 (2012).

[6] Wadikhaye, S. P., Yong, Y. K., and Moheimani, S. R., "A serial-kinematic nanopositioner for high-speed atomic force microscopy," Review of Scientific Instruments 85(10), 105104 (2014).

[7] Xu, Q., "New flexure parallel-kinematic micropositioning system with large workspace," Robotics, IEEE Transactions on $\mathbf{2 8}(2), 478-491$ (2012).

[8] Li, Y. and Xu, Q., "A novel piezoactuated xy stage with parallel, decoupled, and stacked flexure structure for micro-/nanopositioning," Industrial Electronics, IEEE Transactions on 58(8), 3601-3615 (2011).

[9] Xu, Q., "A novel compliant micropositioning stage with dual ranges and resolutions," Sensors and Actuators A: Physical 205, 6-14 (2014).

[10] Berman, B., "3-d printing: The new industrial revolution," Business horizons 55(2), 155-162 (2012).

[11] Meza, L. R., Das, S., and Greer, J. R., "Strong, lightweight, and recoverable three-dimensional ceramic nanolattices," Science 345(6202), 1322-1326 (2014).

[12] Bückmann, T., Stenger, N., Kadic, M., Kaschke, J., Frölich, A., Kennerknecht, T., Eberl, C., Thiel, M., and Wegener, M., "Tailored $3 \mathrm{~d}$ mechanical metamaterials made by dip-in direct-laser-writing optical lithography," Advanced Materials 24(20), 2710-2714 (2012). 
[13] Ostendorf, A. and Chichkov, B. N., "Two-photon polymerization: a new approach to micromachining," Photonics spectra 40(10), 72 (2006).

[14] Cumpston, B. H., Ananthavel, S. P., Barlow, S., Dyer, D. L., Ehrlich, J. E., Erskine, L. L., Heikal, A. A., Kuebler, S. M., Lee, I.-Y. S., McCord-Maughon, D., et al., "Two-photon polymerization initiators for threedimensional optical data storage and microfabrication," Nature 398(6722), 51-54 (1999).

[15] MacDonald, E., Salas, R., Espalin, D., Perez, M., Aguilera, E., Muse, D., and Wicker, R. B., "3d printing for the rapid prototyping of structural electronics," Access, IEEE 2, 234-242 (2014).

[16] Nothnagle, C., Baptist, J. R., Sanford, J., Lee, W. H., and Popa, D. O., "Ehd printing of pedot: Pss inks for fabricating pressure and strain sensor arrays on flexible substrates," in [Proc. of SPIE Vol], 9494, 949403-1 (2015).

[17] Vaezi, M., Kruger, H., and Yang, S., "3d printing of magnetorheological elastomers (mres) smart materials," in [Proc. of the Intl. Conf. on Progress in Additive Manufacturing, Edited by Chua Chee Kai, Yeong Wai Yee, Tan Ming Jen and Liu Erjia], 213-218, Research Publishing Services (2014).

[18] Vaezi, M., Chianrabutra, S., Mellor, B., and Yang, S., "Multiple material additive manufacturing-part 1: a review: This review paper covers a decade of research on multiple material additive manufacturing technologies which can produce complex geometry parts with different materials," Virtual and Physical Prototyping 8(1), 19-50 (2013).

[19] S. Khadraoui, M. Rakotondrabe, P. L., "Optimal design of piezoelectric cantilevered actuators with guaranteed performances by using interval techniques," in [IEEE/ASME - Transactions on Mechatronics], (Oct 2014).

[20] Rakotondrabe, M. and Khadraoui, S., "Design of piezoelectric actuators with guaranteed performances using the performances inclusion theorem and interval tools," in [Smart materials-based actuators at the micro/nano-scale: characterization, control and applications], (2013). Springer.

[21] Rakotondrabe, M., "Performances inclusion for stable interval systems," in [ACC, (American Control Conference)], (2011). 